\title{
Improved use of pulverised fuel ash as general fill
}

\section{G. Winter and B. G. Clarke}

\section{K. S. Li, Victor Li \& Associates Ltd. and University of Hong Kong} The discusser shares the authors' view that the variability of natural soil fills may be not less than that of PFA. Fig. 1A compares the range of variation of the maximum dry density of two common natural soils in Hong Kong-completely decomposed granite (CDG) and completely decomposed volcanics (CDV)-with that of lagoon and conditioned PFA produced by the Castle Peak Power Stations in Hong Kong. ${ }^{1}$ Natural soils with a slightly different grading, even when taken from the same borrow area, may have exhibited quite a significant difference in maximum dry density.

As discussed by the authors, it is impractical to require the contractor to measure the maximum dry density for each consignment of PFA and set a target dry density that changes with each consignment. The writer would like to suggest a method for compaction control of PFA based on a constant target dry density. This will impose some control over the density of the end product, but relieve the difficulties associated with a variable target dry density.

The maximum dry density of PFA, denoted by $\gamma$, can be treated as a random variable with a mean value of $\mu$ and a coefficient of variation of $V$. The desirable dry density based on technical consideration is represented by $\alpha \gamma$, where $\alpha$ is a coefficient. The constant target dry density, $\gamma_{t}$, for compaction control is expressed in terms of the mean value as $\gamma_{\mathrm{t}}=\beta \mu$, where $\beta$ is a coefficient.

If $\alpha \gamma$ is higher than the target dry density, $\gamma_{t}$, it will mean that the PFA has not been compacted to a sufficiently high density. To achieve good compaction control, one would like to limit the probability of exceedance, $p=P\left(\alpha \gamma>\gamma_{\mathrm{t}}\right)$, to an acceptably small value. For fill slopes in Hong Kong, $\mathrm{Ng}$ and Lumb ${ }^{2}$ suggested that $p$ should be limited to less than $15 \%$. That is to say, only $15 \%$ of the fill materials will be allowed to have a dry density less than the desirable dry density. If we assume that $\gamma$ follows a normal distribution, the probability $p$ is simply given as

\begin{tabular}{|l|l|}
\hline I $\quad p=P\left(\alpha \gamma>\gamma_{\mathrm{t}}\right)=P\left(\gamma>\frac{\beta \mu}{\alpha}\right)=\Phi\left(\frac{1-\beta / \alpha}{V}\right)$ \\
\hline
\end{tabular}

where $\Phi(\cdot)$ is the cumulative distribution function of a standard normal distribution. Equation (1) leads to the following relationship for the constant target dry density:

$$
\gamma_{\mathrm{t}}=\alpha \mu(1+t V)
$$

where $t$ has the following values, depending on the probability of exceedance:

$\begin{array}{llll}\text { probability of exceedance, } p & 10 \% & 15 \% & 20 \% \\ t & 1.282 & 1.036 & 0.842\end{array}$

The proposed method of compaction control can be implemented by using typical values for the coefficient of variation, $V$, and the mean maximum dry density, $\mu$. Alternatively, the maximum dry density can be measured and a variable target dry density be adopted for the initial consignments of PFA. Once the values of $V$ and $\mu$ are established, a constant target dry density can be selected based on the desired probability of exceedance using equation (2). 
As an example, suppose that the maximum dry density of PFA is measured to have a mean value of $1.4 \mathrm{Mg} / \mathrm{m}^{3}$ and a coefficient of variation of $8 \%$. If the desirable dry density is 95\% of the maximum dry density-that is, $\alpha=0.95-$ the mean value of desirable dry density is $0.95 \times 1.4=1.33 \mathrm{Mg} / \mathrm{m}^{3}$. If we want to limit the probability of exceedance, $p$, to $15 \%$, the constant target dry density has to be set at higher than $1.33 \mathrm{Mg} / \mathrm{m}^{3}$. According to equation (2), we have

$$
\begin{aligned}
\gamma_{\mathrm{t}} & =\alpha \mu(1+t V) \\
& =0.95 \times 1.4 \times(1+1.036 \times 0.08)=1.44 \mathrm{Mg} / \mathrm{m}^{3}
\end{aligned}
$$

The above method can be extended to account for variability of maximum dry density between sources. However, the use of a constant target dry density for PFA from all sources is not economical because the associated value of $\gamma_{t}$ is likely to be very high to cover a higher overall variability of PFA from all sources. It is preferable to establish a different constant target dry density for PFA supplied from each source.

\section{Authors' reply}

The authors are grateful to Professor Li for his interest in their work, and found his thoughts on a probabilistic approach to the control of the compaction of pulverised fuel ash and other fills very thought-provoking. The data in Fig. 1A are extremely useful, confirming the broad similarity in the variation in maximum dry density between pulverised fuel ash and natural soils.

It is, however, important to set the work on which we were reporting into the context of the way in which such operations on general fill are conducted in the UK. The control of the compaction of natural materials for use as general fill is exclusively by method specification under the Specification for Highway Works. ${ }^{3,4}$ The motivation behind the work was to introduce means of controlling the compaction of pulverised fuel ash in the same relatively simple manner, thus removing any disincentives to the use of pulverised fuel ash where appropriate. In this context we would view the methodology proposed by Professor Li as not achieving our stated intent, by introducing an additional level of complexity to the process.

The foregoing applies to general fill. For more critical applications, such as selected structural fill, an end-product specification is generally applied to all materials. ${ }^{3,4}$ In this instance the methodology proposed by Professor Li may be usefully subject to trial, although the additional costs of implementing a full statistical approach should also be considered.

\section{REFERENCES}

1. LI K. S. Fly ash as a structural fill. Proceedings of the 11 th Southeast Asian Conference on Geotechnical Engineering, Singapore, 1993, pp. 375-380.

2. NG B. W. Y. and LuMB P. Compaction requirement for fill slopes. Journal of the Hong Kong Institution of Engineers, 1980, 8, No. 9, 27-29.

3. SPECIFATION FOR HighWAY WORKS (MCHW 1). Manual of Contract Documents for Highway Works, Volume 1. The Stationary Office, London, 2002.

4. NOTES FOR GUIDANCE IN THE SPECIFICATION FOR HigHWAY WORKS (MCHW 2). Manual of Contract Documents for Highway Works, Volume 1. The Stationery Office, London, 2000. 